\title{
INVESTIGATION OF INFLUENCE OF NANO-REINFORCEMENT ON THE MECHANICAL PROPERTIES OF COMPOSITE MATERIALS
}

\author{
Olga KONONOVA ${ }^{\mathrm{a}}$, Andrejs KRASNIKOVS ${ }^{\mathrm{a}}$, Rimvydas STONYS ${ }^{\mathrm{b}}$, \\ Genadijs SAHMENKO ${ }^{\mathrm{c}}$, Renars VITOLS ${ }^{\mathrm{a}}$ \\ anstitute of Mechanics, Riga Technical University, Ezermalas str. 6, LV-1006, Riga, Latvia \\ ${ }^{b}$ Scientific Institute of Thermal Insulation, Vilnius Gediminas Technical University, \\ Linkmenu g. 28, LT-08217, Vilnius, Lithuania \\ ${ }^{c}$ Institute of Materials and Structures, Riga Technical University, Azenes str. 16/20, LV-1048, Riga, Latvia
}

Received 16 May 2015; accepted 08 Sep 2015

\begin{abstract}
The present work studies the possibility to decrease the formation of micro and nano cracks around short fibres in fibre-reinforced concrete (FRC) composite with the help of nano-reinforcement, which is carbon nanotubes, or micro reinforcement, which is carbon short fibres and nano-fillers. Tensile and bending strength of FRC depends on the spatial distribution of fibres inside a material, type of fibre and cement matrix, as well as an effective micromechanical work of each fibre while pulling out of the concrete matrix. Shrinkage stresses, acting in the matrix in the vicinity of a fibre, lead to the formation of micro-cracks. Such micro-cracks were observed experimentally and were investigated numerically performing broad modelling based on the finite element method (FEM). The investigation was focused on the micromechanical behaviour of a single steel fibre in a cement matrix. Numerical modelling results demonstrated a high level of shrinkage overstresses around steel fibres in concrete. The role of nano and micro admixtures, nanotubes, short carbon fibres as well as the role of water/cement ratio in a high performance concrete matrix, changing (increasing or decreasing) the friction force between the matrix and the steel fibre, were investigated experimentally by way of performing a single fibre pull-out tests. The high scatters of experimental results were obtained in performed pull-out tests. At the same time, for the same series of samples, a positive role of micro and nano admixtures and carbon nanotubes in the increase of pull-out force was recognised.
\end{abstract}

Keywords: fibre concrete, pull-out, nano admixture, cement matrix.

\section{Introduction}

The role of fibres. Concrete is a brittle material that has low fracture deformation. Last few decades have been associated with the investigation of novel concrete types: high strength, high performance and ultra-high performance concretes (UHPC) and their appearance on the market (Schmidt, Fehling 2005). Such materials combine the increasing compressive strength with relatively weak load-bearing capacity under tensile loads. It should be mentioned that the increase in compressive strength of such materials is mainly concerned with more dense internal micro and nano structure of a material, which is the reason that triggers the explosive-like failure under axial compression. A possible solution to such problems is the use of short fibres distributed in concrete. Fibres can be added into concrete to improve its bending and tensile load bearing capacity as well as to make brittle concrete to behave quasi-plastically and to detain crack formation.

The conventional technology of fibre-reinforced concrete (FRC) is about the addition of fibres into a con- crete mix, mixing, filling a mould and curing. The application of external loads leads to internal stress, FRC deformation as well as formation and widening of micro and macro cracks. Fibres bridge cracks and provide resistance to crack opening. Every fibre that bridges a crack is stretched. The increase in external loads leads to cylindrical the initiation of a debond crack and its running between the fibre and concrete matrix. Once the debonding crack reaches the whole length of one end of a fibre, it starts to pull out (Mobasher, Li 1995; Kononova et al. 2012; Krasnikovs et al. 2009, 2010; Li, Mobasher 1998). Fibre pull-out from a concrete matrix has a main role in the mechanical behaviour of FRC in the post-cracking stage.

Fibre-matrix interface. Short fibres carry loads in cracked FRC. In terms of any particular fibre in concrete, it is important to consider mechanical properties of fibreconcrete matrix interface, the interface debonding mechanisms and overstress distribution in its vicinity. Intensive investigations of fibre-matrix interfaces commenced with

Corresponding author: Rimvydas Stonys

E-mail: rimvydas.stonys@vgtu.lt 
works by Bentur and Kovler (2003), Bentur (2000), Wille and Naaman (2010). Li and Stang (1997), Htut and Foster (2010) reviewed pull-out tests of single and multiple fibres aimed at finding a different way to characterise the mechanical behaviour of the interface. A number of research efforts focused on interface bond interpretation based on the ultimate tensile strength (Krasnikovs et al. 2009, 2010; Li 1992; Li et al. 1993; Stang et al. 1995) or based on parameters of fracture mechanics (Pupurs 2012; Pupurs et al. 2013; Cheng, Mobasher 1998). This work focuses only on the mechanical side of the fibre interface bond and the work of straight steel fibres. The mitigation of each fibre pull-out process is a very important problem for concrete with dispersedly distributed fibres. A number of papers (Li 1992; Li et al. 1993; Stang et al. 1995) addressed various fibre and matrix strengthening techniques, such as fibre form and shape variation, fibre surface modification and treatment as well as concrete matrix densification.

\section{Shrinkage of a concrete matrix and its effect on the formation of overstress around steel fibres}

Cement hydration process is associated with shrinkage processes. Different types of shrinkage can be mentioned, such as autogenous, carbonation, drying, etc. Fibres restrict shrinkage of a cement matrix, which results in overstress. Cracks occur under tensile overstress, which is exceeded tensile strength of the cement matrix. Therefore, the material around every fibre in concrete is subjected to overstresses. Drying shrinkage is higher in areas close to external surfaces of a structural element, at the same time, in the framework of the present investigation we will not try and separate these different types of shrinkages and only consider shrinkage in general. Absolute values of shrinkage deformation for different concretes

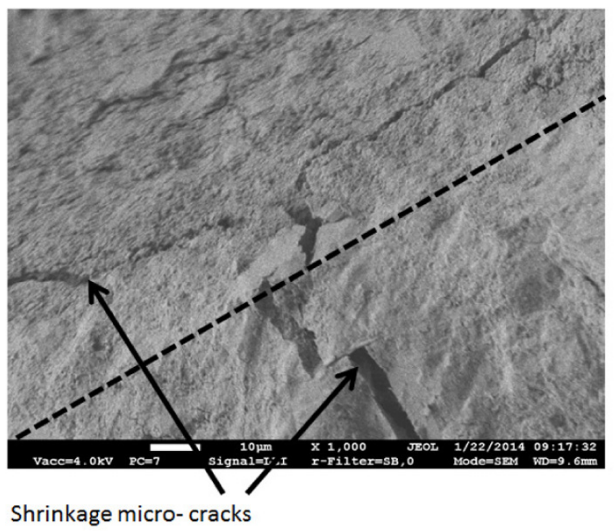

a) b)

Fig. 1. a) SEM image of the steel fibre channel in a concrete matrix. Dotted lines show the place of steel fibre. The photo shows an internal surface of the cavity made in concrete by the fibre; b) SEM image of an internal surface of the cavity made by steel fibre in a concrete (above the dotted line) and the concrete matrix around the fibre, covered by an orthogonal to fibre direction and oriented along the fibre shrinkage cracks vary in a range between $0.0002 \mathrm{~mm}$ per one $\mathrm{mm}$ and $0.001 \mathrm{~mm}$ per one $\mathrm{mm}$ (ACI 2008). In early age hydration, values of shrinkage deformations are smaller than above-mentioned values, and strength of early age concrete is low as well.

In order to detect the formation of micro-cracks in the contact zone of the fibre-cement matrix, three types of concrete matrixes were investigated, namely a low strength, a normal strength and a high strength matrix (data on the matrixes is provided below). Samples after the steel fibre pull-out test were split along the plane, which passes the empty channel of the fibre (after splitting, some pieces were burnished to reach this plane). Then, sample surfaces were investigated, using an electron-scanning microscope. In all types of a cement matrix, deep longitudinal and orthogonal cracks (oriented against the direction of the fibre) were observed. Figure $1 \mathrm{~b}$ shows the microstructure of a normal strength cement matrix around the fibre channel.

\section{Numerical investigation of shrinkage overstresses around steel fibres}

Numerical modelling, based on the finite element method (FEM), was performed aiming to evaluate possible crack formation around steel fibres in concrete. Commercial software Solid Works was used. Straight cylindrical form steel fibre surrounded by a concrete matrix was observed. The numerical model was used and the cement matrix was considered as a homogeneous and isotropic material. For practically important fibre concentrations in concrete (concentrations used in real fibre concretes), the average distance between fibres is traditionally higher than a single fibre length, this is why an interaction between adjacent fibres was neglected (the interaction between their overstress fields). Commercially available round cross section steel fibres usually have a length to diameter ratio $L / D$ equal or more than 30 . Let us observe the concrete ring encircling the fibre at its middle part far from both ends. Let us take out a fibre from the matrix ring. The matrix ring will have no loads or stresses on its internal and external cylindrical surfaces. The internal cylindrical channel radius is equal $R=D / 2$. Then, the ring material will be exposed to shrinkage deformations. The internal diameter of the ring will decrease reaching the radius of $R-\Delta$.

Stress condition caused by concrete matrix shrinkage around the fibre was calculated by inserting a steel fibre into the channel in the concrete matrix having the initial external radius $R$ (and determining contact conditions between the fibre and concrete matrix surfaces). According to the symmetry, only one-fourth part of the fibre surrounded by the matrix was used in calculations. Symmetry conditions were used on radial planes of the model. Figures 2-6 show the calculation results obtained for the fibre having the length of $L=5 \mathrm{~mm}$ and the diameter of $D=1 \mathrm{~mm}$, which was inserted in the concrete matrix cylinder, having the following external dimensions: the 

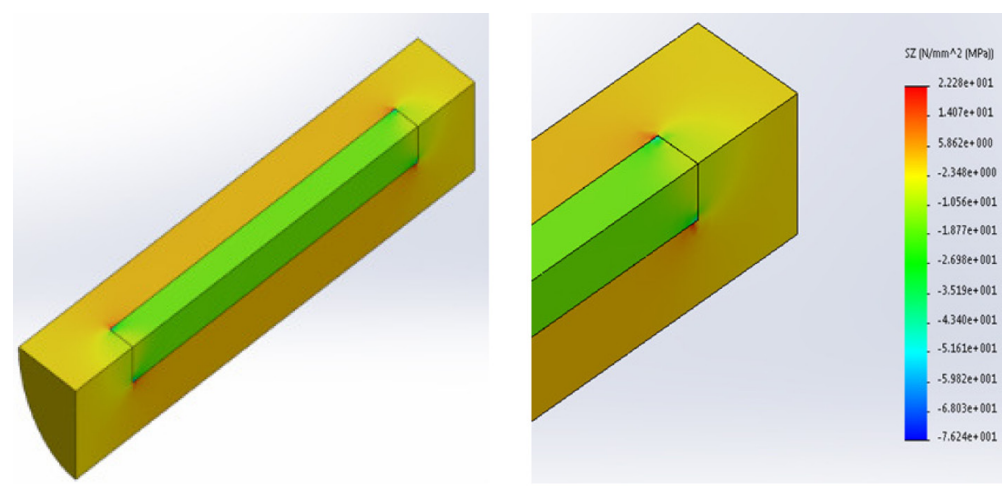

Fig. 2. Stress $\sigma_{z z}$ distribution in a steel fibre and concrete matrix due to the matrix shrinkage of $0.0002 \mathrm{~mm} / \mathrm{mm}$

length of $7 \mathrm{~mm}$ and the diameter of $2 \mathrm{~mm}$ and the internal cylindrical cavity with the length of $5 \mathrm{~mm}$ and the diameter $D=(1-2 \Delta) \mathrm{mm}$, when $\Delta=0.1 \mathrm{~mm}$.

The stress $\sigma_{z z}$ distribution in the matrix and in the fibre is shown in Figure 2. Mechanical parameters of the matrix and steel were as follow: the concrete Young modulus $E_{c}=30 \mathrm{GPa}$; the Poison's ratio $v_{c}=0.2$; the steel fibre elastic modulus $E_{f}=200 \mathrm{GPa}$ and the Poison's ratio $v_{f}=0.3$. The stresses distributions along the line $\mathrm{AB}$ in the concrete matrix, depending on the shrinkage value $\Delta$ are shown in Figures 3a-3c. Peaks on graphs correspond to singular stress distributions in the vicinity of corners from fibre ends. The real geometrical form and shape of fibre ends depend on fibre production technology and usually have a round form (or partially round). It means that additional investigation of overstresses is necessary for every particular type of fibre, with its ends geometry in regions of the matrix located close to fibre ends. This work focuses on overstresses in the concrete matrix in the middle part of the fibre. Numerical calculations were performed on fibres having the length equal to $30 \mathrm{~mm}$. Stresses in the middle part of the fibre were practically the same as for the fibre, which was $5 \mathrm{~mm}$ long (for stresses in the concrete on the surface of the fibre at its half-length, the difference was less than $2 \%$ ). Therefore, this article gives figures for fibres that are $5 \mathrm{~mm}$ long.

The value of the shrinkage parameter $\Delta$ equal to $0.001 \mathrm{~mm}$ per $\mathrm{mm}$ corresponds to concrete having a high level of shrinkage deformations. It may be concrete with high water-to-cement ratio. $\Delta$ equal to 0.0005 and $0.0002 \mathrm{~mm}$ per $\mathrm{mm}$ belongs to concretes with the middle and small range of shrinkage deformations. Numerically obtained circumferential and longitudinal stresses are high compared to the tensile strength of concrete, which varies in the range from $2.5 \mathrm{MPa}$ to $6 \mathrm{MPa}$ (for early age concrete, the tensile strength is still lower). These stresses exceed the concrete strength in case of concretes with high and middle range shrinkage (ordinary concretes). Cracks orthogonal to the direction of fibre as well as cracks along the fibre will be formed in such concretes, which was observed experimentally (Fig. 1). With the goal to evaluate the decrease in stress fields in the concrete matrix, going away from the fibre surface, stress

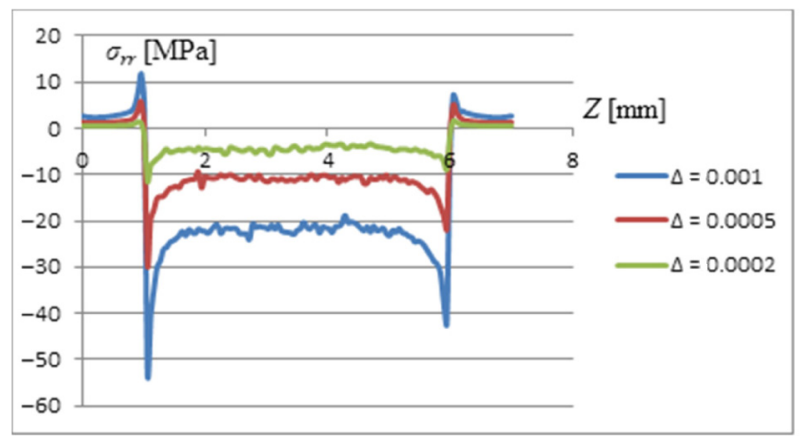

Fig. 3a. Radial stress $\sigma_{r r}$ in the concrete matrix along line $\mathrm{AB}$ (see Fig. 4a) depending on shrinkage parameter $\Delta$

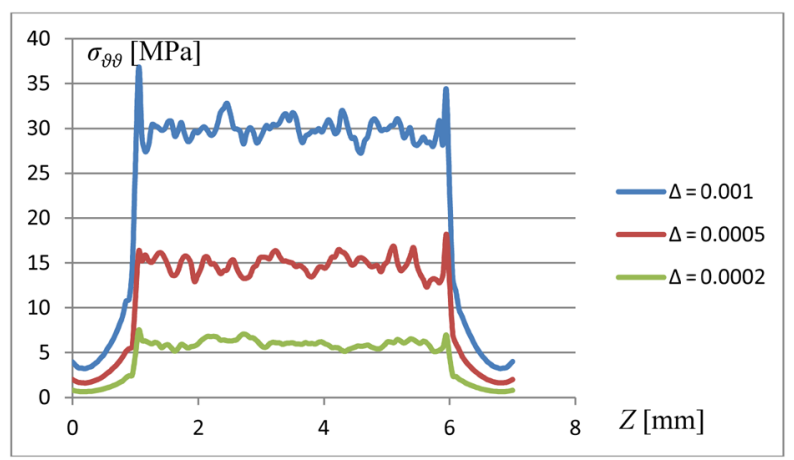

Fig. 3b. Circumferential stress $\sigma_{\theta \theta}$ in the concrete matrix along the line $\mathrm{AB}$ (see Fig. 5a) depending on the shrinkage parameter $\Delta$

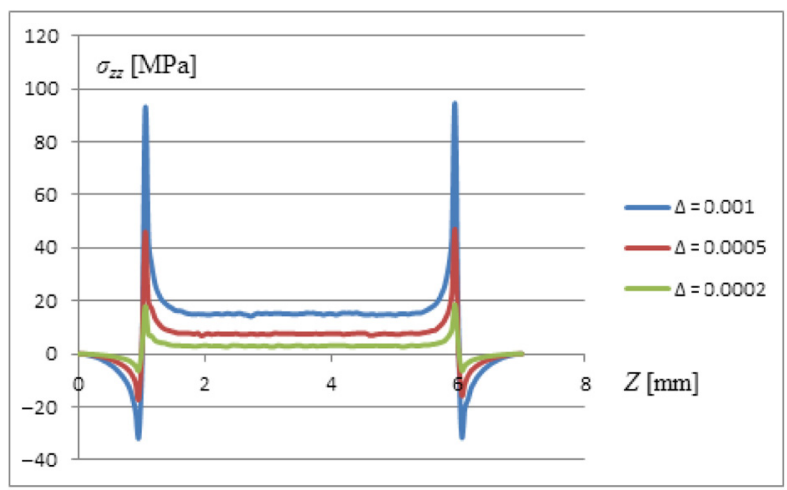

Fig. 3c. Longitudinal stress $\sigma_{z z}$ in the concrete matrix along the line $\mathrm{AB}$ (see Fig. 5a) depending on the shrinkage parameter $\Delta$ 


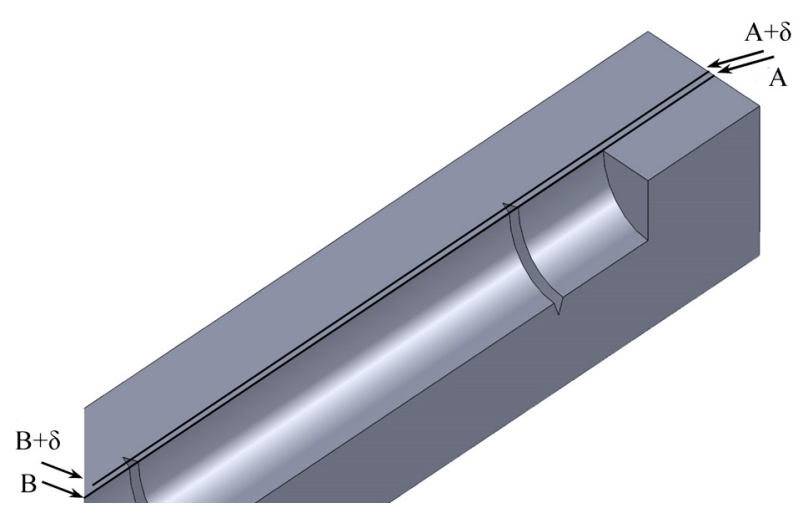

Fig. 4. Geometrical lines in the concrete matrix, along which calculated stress values are shown

fields were calculated on lines parallel to the fibre surface (see Fig. 4). Stresses are smoothly decreasing in the concrete increasing the distance from the fibre surface. Validating the obtained numerical results, FEM calculations were compared with the analytical solution (1) existing for a thick endless cylinder subjected to the internal deformation $\Delta$ equal to $0.0002 \mathrm{~mm}$ per mm (Hearn 1997):

$$
\sigma_{r r}\left(\frac{r_{1}}{E_{f}}\left(1-v_{f}\right)+\frac{r_{1}}{E_{m}}\left(\frac{r_{2}^{2}+r_{1}^{2}}{r_{2}^{2}-r_{1}^{2}}+v_{m}\right)\right)=\Delta,
$$

where $r_{1}$ is the inner radius of the matrix; $r_{2}$ is the outer radius of the matrix. The analytical solution for $\sigma_{r r}$ stress, in the concrete matrix on the surface of the fibre, at its half-point is equal to $3.56 \mathrm{MPa}$ and obtained numerically (using FEM) $3.59 \mathrm{MPa}$.

A numerical simulation was made of steel fibre surrounded by a concrete matrix with two orthogonal to fibre direction and symmetrically located disk-like cracks in a case of concrete matrix shrinkage and different crack dimensions. Figures $5 \mathrm{a}-5 \mathrm{c}$ show the stress distributions around a fibre with two symmetrically located cracks of a different length $(\delta=0.1 \mathrm{~mm}$ and $\delta=0.5 \mathrm{~mm})$. The analysis of the stress pictures shows a rather high level of tensile stresses in the concrete close to the fibre surface between cracks. This means that the next crack can be triggered. The cracking process will form disk-like cracks oriented perpendicularly to the direction of the fibre. In the beginning, the cracking process is random. Then, a new crack appears between two adjacent cracks. This process continues until saturation (as soon as overstress fields of adjacent cracks start to decrease the overstress level between two cracks). The length of shrinkage cracks needs an additional investigation using the approach of fracture mechanics. Looking at overstress pictures, it is possible to see that for every level of shrinkage exists a crack length, at which a crack has a tendency to stop (Fig. 5c). It is obvious that the real network of microcracks and nano-cracks affects the pull-out process of every steel macro fibre.

\section{Modification of the concrete structure}

During few last decades, numerous investigations were made in the field of concretes having a high packing density of the material, focusing on the addition of micro and nano-particles into the cement matrix (Hecht 2012; Sanchez, Sobolev 2010; Naaman, Wille 2012).

Such materials are known as high strength, high performance or ultra-high performance concretes (UHPC) (Sanchez, Sobolev 2010). Some modern directions focus on nano-modified cement matrixes, the use of nano-sized fibres (nanotubes) and short micro-sized fibres in a concrete mix.

In earlier days, the term "nanotechnology" was associated with the creation and production of nano-objects

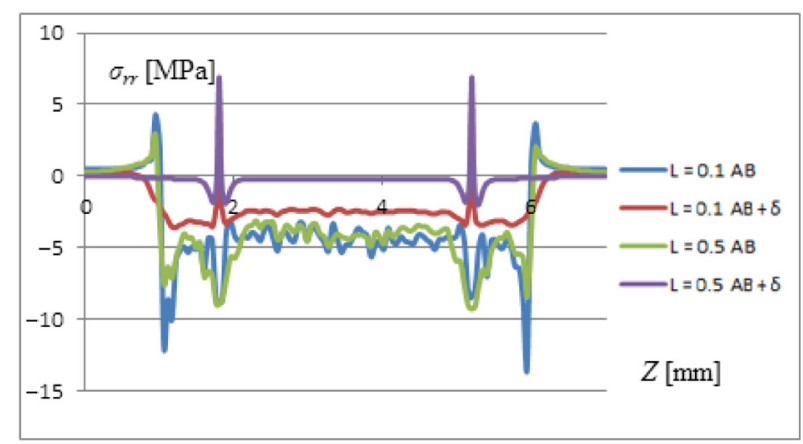

Fig. 5a. Radial stress $\sigma_{r r}$ in the concrete matrix along the lines $\mathrm{AB}$ and $\mathrm{AB}+\delta$

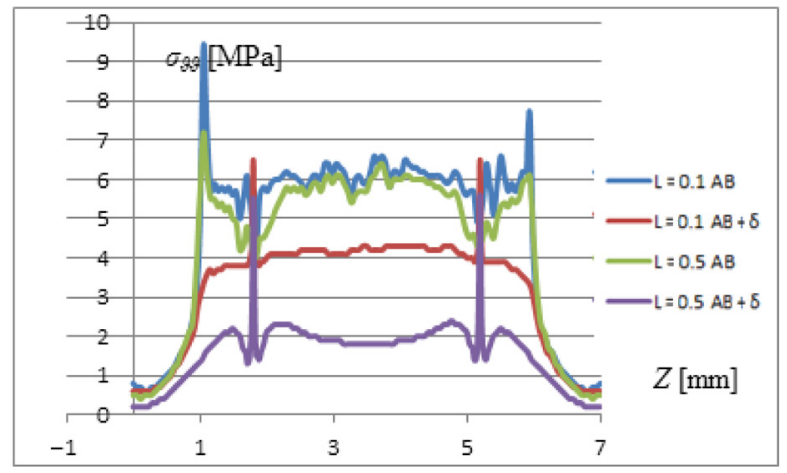

Fig. 5b. Circumferential stress $\sigma_{\theta \theta}$ in the concrete matrix along the lines $\mathrm{AB}$ and $\mathrm{AB}+\delta$

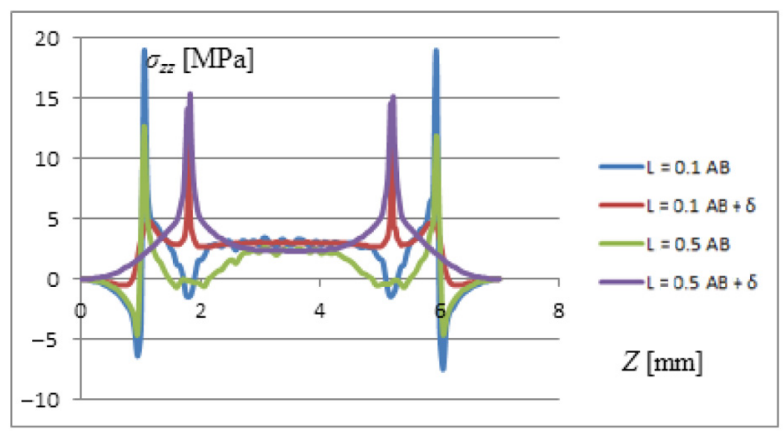

Fig. 5c. Longitudinal stress $\sigma_{z z}$ in the concrete matrix along the lines $\mathrm{AB}$ and $\mathrm{AB}+\delta$ 
with dimensions smaller than $100 \mathrm{~nm}$. Nowadays, some principles of nanotechnology are used in the concrete industry (Hecht 2012). Multi-sized aggregate (filler) system, including macro, micro and nano-particles is the basic condition for dense microstructural packing. The most important component of high-performance concrete is pozzolanic filler, consisting of micro and nano-sized amorphous silicate or alumosilicate particles.

Ultra High-Performance Fibre Reinforced Concrete (UHPFRC) is characterized by high cement and pozzolan content, extremely low water/cement ratio, very high compressive strength $(>150 \mathrm{MPa})$ and high bending strength $(>15 \mathrm{MPa})$. The interface between the mechanical behaviour of fibre and matrix determines the post-cracking behaviour, the bearing capacity of FRC, the fracture energy as well as the reliability of structural elements. The high value of autogenous shrinkage is the main drawback of high-strength concrete with the water/ cement ratio smaller than 0.25 (Justs et al. 2014).

The interaction between fibre and matrix may be evaluated experimentally by a single fibre pull-out test. Traditionally, a pull-out test sample consists of one or two concrete (mortar) parts with embedded fibre. The sample is fixed to special grips of the testing machine. The sample is stretched and the current value data of the applied load and the corresponding displacement between the grips are collecting in on-line regime, allowing to obtain fibre pulled out length - applied tensile force diagram by Šahmenko et al. (2007). Numerous studies have proved the determining role of the steel fibre geometry (Naaman, Wille 2012) in the pull-out process. Straight and smooth fibres have the lowest value of the pull-out energy (measuring as an area under the pull-out diagram). Traditionally, a fibre with hooked ends demonstrated the maximal pull-off force, which was 2.5 times higher. However, the undulated fibre demonstrated the value of the pulloff force, which was seven times higher, as well as a much higher pull-out energy compared with the straight one (Šahmenko et al. 2007). The use of carbon nanotubes as nano-sized reinforcement is a very exciting and interesting research direction in the area of cement and concrete technologies. Carbon nanotubes can be rolled from graphite sheets and multi-walled carbon nanotubes (MWCNT) consist of a number of layers (Sasmal et al. 2013). The diameter of MWCNT is $10-20 \mathrm{~nm}$. Reported results regarding the change in mechanical properties of concrete (and fibre concrete) because of the addition of MWCNT (in the range of 0.0024 to $0.5 \%$ by mass of the cement binder) are very controversial. One of the experimental studies (Wille, Loh 2010) revealed that a small amount $(0.022 \%$ of the cement amount) of MWCNT significantly improved the bonding behaviour of a single pulled-out fibre. At the same time, the influence on the compressive strength has not been detected.

During concrete maturing, shrinkage creates overstressed areas in the concrete matrix. Overstress leads to the formation of micro and nano cracks in the matrix.
A wise use of nano-reinforcement may decrease the number of micro-cracks, finally increasing the fibre pull-out force.

\section{Experimental investigation}

The task of the experimental part is to evaluate the influence of different factors on the fibre pull-out behaviour, such as: the type of the cement matrix (using low strength, normal strength and high strength cement matrixes); the influence of the cement matrix modification by MWCNT, and the influence of the cement matrix modification by short carbon fibres.

Mix design and materials. In the concrete mix, the preparation of alite-based white Portland cement CEM I $52.5 \mathrm{R}$ was used as the binding agent with naturally fractioned and washed quartz sand as the main filling agent. Ground quartz sand and silica fume (Elkem "Microsilica 920 Densified") were used as micro fillers. The obtained SEM images of used silica fume showed a high amount of particles smaller than $100 \mathrm{~nm}(>15 \%)$; therefore, this material may be classified as micro/nano admixture. Polycarboxilate-based super plasticizer was used to control the workability of the mix.

The first set was designed to model the part of the concrete matrix of practically used concrete mixes with different compressive strengths. Tree types of cement matrixes were produced and tested (Table 1). The first type of concrete was low strength (LS) with the cement content of $400 \mathrm{~kg} / \mathrm{m}^{3}$, without silica fume and water-tocement (W/C) ratio equal to 0.75 and filler/cement ratio equal to 4.1. The second type of concrete was normal strength concrete (NS) with the cement content of $550 \mathrm{~kg} / \mathrm{m}^{3}$, with silica fume, W/C ratio equal to 0.55 and filler/cement ratio equal to 2.7. The third type of concrete was high-strength concrete (HS) with the cement content of $800 \mathrm{~kg} / \mathrm{m}^{3}$, silica fume, the W/C ratio of 0.25 and the filler/cement ratio of 1.6. The amount of micro-filler was adjusted in order to achieve the paste content of $60 \pm 3 \%$ by volume in all cases. The mix compositions are summarized in Table 1. Mixes were modified with multi-wall carbon nanotubes (MWCNT) Graphistrength CW2-45. They are characterized by each nanotube with the diameter of $10-15 \mathrm{~nm}$ and a high aspect ratio $(>100)$. The water dispersion of $2 \%$ concentration of MWCNT was preliminarily prepared by ultrasound and was used as an admixture. The solution of nanotubes was added to concrete mixes in the amount of $10 \mathrm{l} / \mathrm{m}^{3}$, which corresponds to $200 \mathrm{~g}$ of nanotubes in $1 \mathrm{~m}^{3}$. Correspondingly, in HS, NS and LS mixes, amounts of MWCNT were equal to $0.05 \%, 0.072 \%$ and $0.10 \%$ of the cement weight.

The second experimental set is based on high-strength composition with the cement content of $800 \mathrm{~kg} / \mathrm{m}^{3}$. Experiments were carried out in order to define the influence of MWCNT, short carbon fibres (the diameter of $7 \mathrm{~mm}$ and the length of $12 \mathrm{~mm}$ ), as well as the combination of carbon fibre and nano-tubes together. The prepared matrix types were: 5 MIX - Reference; 6 MIX - Carbon fibres; 
Table 1. Tree types of cement matrixes produced and tested

\begin{tabular}{l|l|l|l|l|l|l|l|l|l|l}
\hline & HS & HS-NT & NS & NS-NT & LS & LS-NT & $\begin{array}{c}\text { HS } \\
\text { MIX5 }\end{array}$ & $\begin{array}{c}\text { HS } \\
\text { MIX6 }\end{array}$ & $\begin{array}{c}\text { HS } \\
\text { MIX7 }\end{array}$ & $\begin{array}{c}\text { HS } \\
\text { MIX8 }\end{array}$ \\
\hline Cements I 52.5 R Aalborg & 1.000 & 1.000 & 1.000 & 1.000 & 1.000 & 1.000 & 1.000 & 1.000 & 1.000 & 1.000 \\
\hline Sand Quartz 0.3/1 mm & 1.000 & 1.000 & 1.455 & 1.455 & 2.000 & 2.000 & 1.500 & 1.500 & 1.500 & 1.500 \\
\hline Sand Quartz fine 0/0.3 & 0.375 & 0.375 & 0.727 & 0.727 & 1.500 & 1.500 & 0.000 & 0.000 & 0.000 & 0.000 \\
\hline Quartz micro filler & 0.083 & 0.083 & 0.455 & 0.455 & 0.625 & 0.625 & 0.375 & 0.375 & 0.375 & 0.375 \\
\hline Silica Fume 920 D & 0.167 & 0.167 & 0.091 & 0.091 & 0.000 & 0.000 & 0.175 & 0.175 & 0.175 & 0.175 \\
\hline MWCNT, 2\% dispersion & 0.000 & 0.025 & 0.000 & 0.036 & 0.000 & 0.050 & 0.000 & 0.000 & 0.029 & 0.029 \\
\hline MWCNT, calculated as dry & 0.000 & 0.00050 & 0.000 & 0.00072 & 0.000 & 0.0010 & 0.000 & 0.000 & 0.00058 & 0.00058 \\
\hline Carbon fibre 7 $\mu \mathrm{m} / 15 \mathrm{~mm}$ & & & & & & & - & 0.014 & - & 0.014 \\
\hline Water & 0.250 & 0.250 & 0.545 & 0.545 & 0.750 & 0.750 & 0.286 & 0.286 & 0.286 & 0.286 \\
\hline Superplasticizer & 0.030 & 0.030 & 0.009 & 0.009 & 0.008 & 0.008 & 0.030 & 0.030 & 0.030 & 0.030 \\
\hline
\end{tabular}

7 MIX - MWCNT; 8 MIX - MWCNT + Carbon fibres. The compressive strength was determined in accordance with the standard LVS EN 12390-3 (2002) for the ages of 10 and 28 days. The compression testing machine Controls 50-C56G2 was used, applying the rate of loading of $0.9 \mathrm{MPa} / \mathrm{s}$. Pull-off test specimens were prepared using a single steel fibre of the length of $50 \mathrm{~mm}$, the diameter of $0.8 \mathrm{~mm}$ and the tensile strength of $1050 \mathrm{MPa}$. The fibre was symmetrically ( $25 \mathrm{~mm}$ on each side) incorporated in the concrete matrix. After casting, samples were covered by polyethylene film, and after two days, samples were demoulded and cured in a water environment. 12 hours before testing, the samples were removed from the water. Single fibre pull-out tests were made using the universal testing machine Zvick Z150. A sample with incorporated fibre was loaded using specially designed grips as described by Kononova et al. (2012). The mutual displacement rate of grips was equal to $5 \mathrm{~mm} / \mathrm{min}$ and was provided during the whole test. The fibre pulling out displacement was controlled by video extensometer.

\section{Experimental results and discussions}

Compressive strength. Results of the tests for compressive strength are presented in Figure 6a. It must be noted, that HS and NS compositions with carbon nanotubes are characterised by a little decrease in compressive strength values, changing in the range of $5-18 \%$, comparing to samples without nanotubes. Three samples of each mix were tested after 10 days and three - after 28. For LS mixes, strength reduction was smaller. The phenomenon of the reduction in strength may be explained as the side effect of MWCNT, e.g., the presence of dispersing agents and air-entraining effect in this situation.

Fibre pull-out tests. High variation of pull-out results is found between tree types of cement matrixes. The average fibre pull-out force for basic mixes of the low-strength matrix was $16 \mathrm{~N}$, for the normal-strength matrix $-77 \mathrm{~N}$ and for the high-strength matrix $-140 \mathrm{~N}$. All compositions with nanotubes showed higher pull-out force values compared to basic mixes: the average fibre pull-out force for basic mixes of the low strength matrix was approx. $46 \mathrm{~N}$, for the normal strength matrix - approx. $95 \mathrm{~N}$ and for the high-strength matrix - approx. 226 N. Pull-out averaged maximum forces and deviations of results are summarised in Figure 6b. Diagrams characterising fibre pull-out diagrams are given in Figure $6 \mathrm{~b}$. Big scattering of pull-out test results should be noted, but in spite of this fact, the positive influence of adding carbon nanotubes is evident. The improvement of pull-out behaviour was proved for low strength, normal strength, as well as high strength cement matrixes. The influence of the modification of the cement matrix by carbon fibre

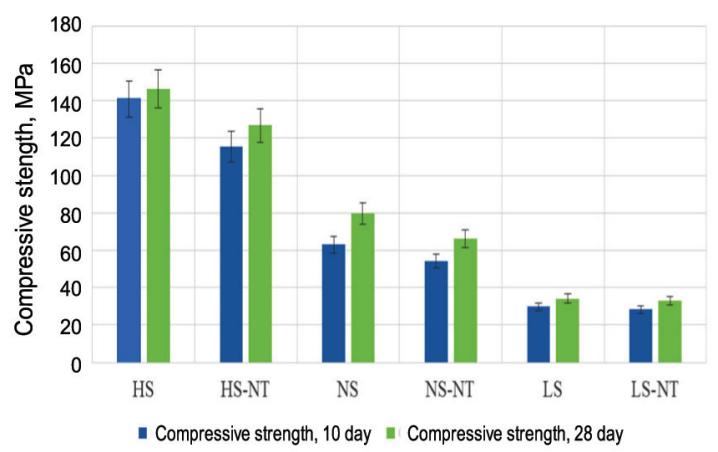

a)

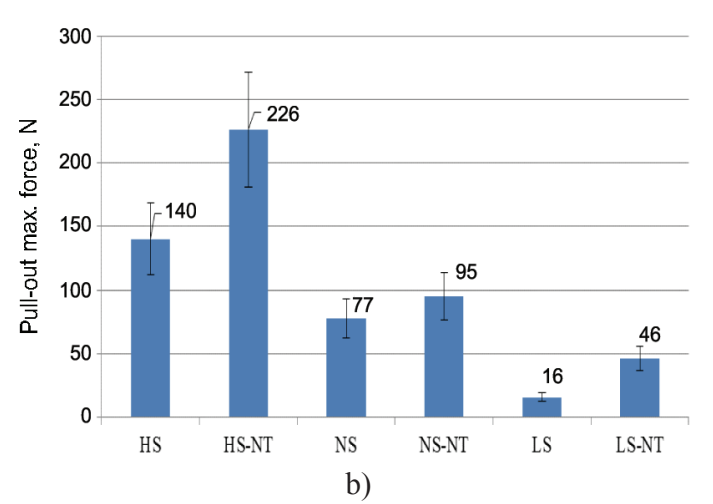

Fig. 6. a) Results of compressive strength; b) Averaged maximum forces of pull-out (the diagrams show the scatter of results averaging data over nine samples) 


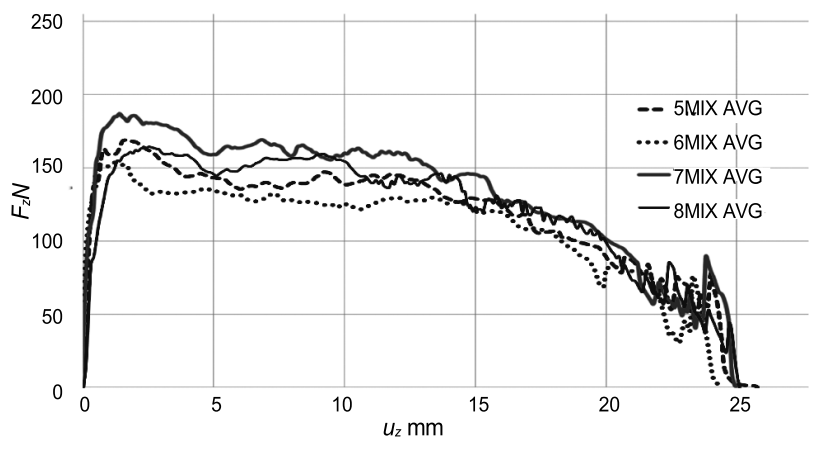

Fig. 7. Pull-out response results for a single fibre pull-out of the concretes designated as MIX 5 - reference concrete; MIX 6 - concrete with carbon fibres; MIX 7 - concrete with MWCNT; MIX 8 - concrete with MWCNT and carbon fibres. The diagram presents experimental data for each concrete mix averaged over nine samples. Along the vertical axis, the pulling force is applied, and along the horizontal axis - the length of the pull-out fibre

and MWCNT are investigated in the second experimental set. Nine samples were tested for each composition.

This allowed to evaluate results objectively. Averaged curves are shown in Figure 7. Comparing the pullout curves of a single steel fibre, it is possible to conclude that the addition of short carbon fibres (6 MIX) decreased the pull-out force. It can be explained by the lower homogeneity of the resultant cement matrix (6 MIX), compared with the reference matrix (5 MIX). It must be mentioned that such a situation is characteristic of a straight shape steel fibre, used in this case. At the same time, other pull-out experiments with a curved geometry steel fibre resulted in a positive clumping effect when the cement matrix was modified by short straight micro fibres (Wille, Loh 2010; Chung 2000; Šahmenko et al. 2007). The mix containing carbon nanotubes (7 MIX) showed a higher clumping effect. On average, the mix with the composition of carbon nanotubes and nano fibres (8 MIX) demonstrated the same clumping behaviour

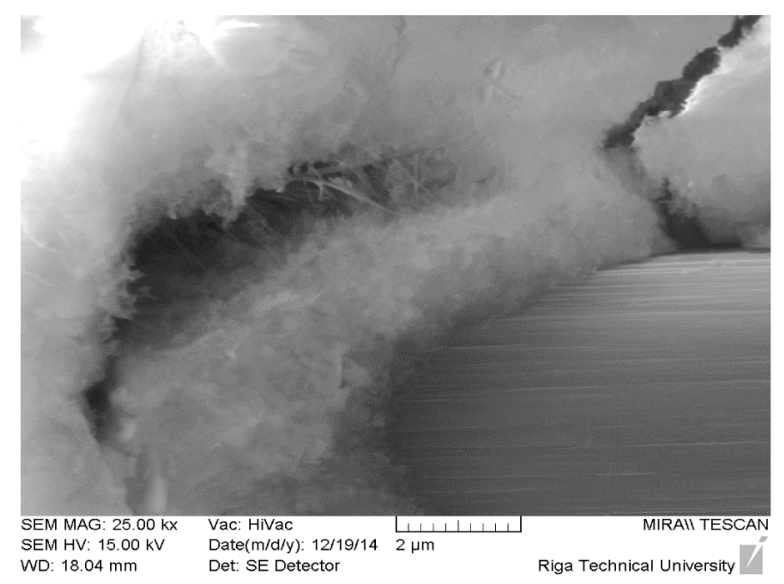

a) as the reference mix. Microscopic investigations of the concrete with carbon fibres and carbon nanotubes demonstrated a dense microstructure of the cement matrix and rather a homogeneous hardened cement paste, consisting of quartz sand aggregate and amorphous C-S-H (Fig. 8b). Using higher magnification, a carbon nanotube, which crosses the shrinkage micro crack (white arrow) in the vicinity of the carbon fibre, can be recognised (Fig. 8b). In the right corner of Figure 8b, it is possible to recognise the shrinkage crack, which is situated along the carbon fibre. The reason for the formation of such crack in the vicinity of the carbon fibre is the circumferential stress $\sigma_{\theta \theta}$ (similarly as it was calculated for the steel fibre and is shown in Fig. 5b). This fact confirms a positive role of carbon nanotubes, which may be explained by bridging micro cracks and preventing crack propagation. As a result, the effect of the increasing fibre pull-out force is achieved. Investigations resulted in the discovery of the micro-structure of the cement matrix modified with MWCNT as well as with nano-fibres, hypothetically, covered by C-S-H gel. It must be noted, that the diameter of such fibres was approximately $100 \mathrm{~nm}$ to $300 \mathrm{~nm}$, it is much more than the diameter of MWCNT (10-20 nm) and much smaller than the diameter of the carbon fibre $(7000 \mathrm{~nm})$. The effect of MWCNT modification during the cement hydration should be studied in more detail in the future.

\section{Conclusions}

The paper focused on detailed experimental and parametric numerical investigation of shrinkage cracks. It was demonstrated that shrinkage overstresses in a concrete matrix, in the vicinity of a steel fibre lead to the formation of micro and nano cracks. Numerically obtained circumferential and longitudinal stresses for the shrinkage parameter $\Delta$ were equal to 0.0005 and $0.0002 \mathrm{~mm} / \mathrm{mm}$. This is high in comparison to the tensile strength of the concrete, which varies in the range from $2.5 \mathrm{MPa}$ to $6 \mathrm{MPa}$. These

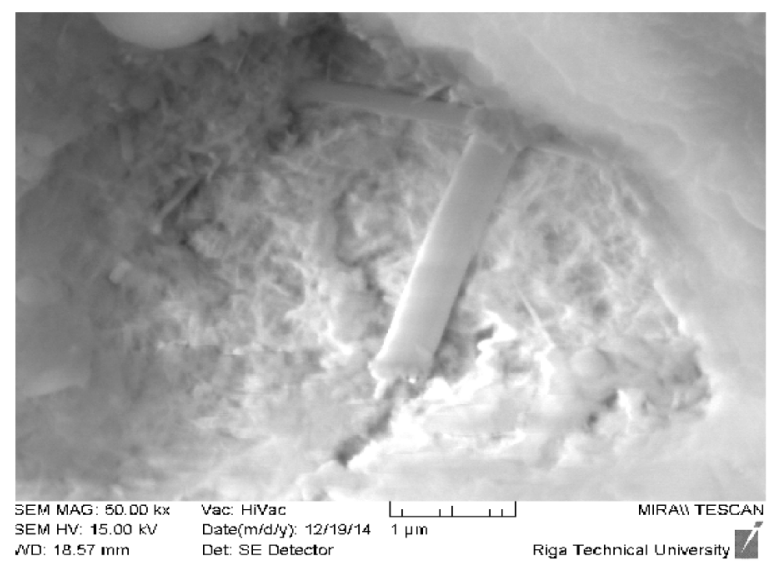

b)

Fig. 8. a) SEM image of a carbon nanotube crossing the crack (white arrow) in the vicinity of a carbon fibre; b) SEM image of carbon nanotubes crossing an amorphous area 
stresses exceed concrete strengths in terms of concretes with high and middle range shrinkage. According to experimental observations, cracks orthogonal to the direction of the fibre as well as cracks along the fibre form in such concretes. Aiming to evaluate the decrease in stress fields in the concrete matrix with a different length of shrinkage cracks, stress fields were numerically (using FEM) calculated. Looking at overstress pictures along the lines parallel to the fibre surface, it is possible to see that for every level of shrinkage exists a crack length, at which the crack will have a tendency to stop. Shrinkage cracks decrease the pull-out force for every particular fibre. Such cracks affect the macro fibre pull-out process. The addition of a nano filler improves the situation. Differences in pull-out forces were detected: the normal strength composition showed a 5 times higher result, but high-strength composition showed a 9 times higher result compared to with the low strength cement matrix. Adding a small amount of MWCNT demonstrates a tendency to improve the pull-out behaviour in all experimental series. Carbon nanotubes and short carbon fibres are bridging micro and nano cracks in the vicinity of the macro fibre. No pronounced positive result was found by adding short carbon fibres for straight steel macro fibre clumping. Experimental results confirmed that the highest effect on macro fibre clumping in the concrete matrix can be obtained using a high strength concrete matrix with carbon nanotubes and micro/nano admixture, such as silica fume.

\section{Acknowledgements}

This research was supported by Riga Technical University through the Scientific Research Project Competition for Young Researchers No. 2014/26.

\section{References}

ACI. 2008. Guide for modeling and calculating shrinkage and creep in hardened concrete. Reported by ACI Committee 209, ACI 209.2R-08.

Bentur, A. 2000. Role of interfaces in controlling the durability of fiber-reinforced cements, Journal of Materials in Civil Engineering 12(1): 2-7. http://dx.doi.org/10.1061/(ASCE)0899-1561(2000)12:1(2)

Bentur, A.; Kovler, K. 2003. Evaluation of early age cracking characteristics in cementitious systems, Materials and Structures 36(3): 183-190.

http://dx.doi.org/10.1007/BF02479556

Cheng, Y. L.; Mobasher, B. 1998. Finite element simulations of fiber pullout toughening in fiber reinforced cement based composites, Advanced Cement Based Materials 7(3-4): 123-132.

Chung, D. D. L. 2000. Cement reinforced with short carbon fibers: a multifunctional material, Composites: Part B 31: 511526. http://dx.doi.org/10.1016/S1359-8368(99)00071-2

Hearn, E. J. 1997. Mechanics of materials 1. $3^{\text {rd }}$ ed. Oxford: Butterwort-Heinemann. $450 \mathrm{p}$.

Hecht, M. 2012. Practical use of fiber-reinforced UHPC in construction - production of precast elements for WildBrücke in Völkermarkt, in Proceedings of Hipermat 2012, $3^{\text {rd }}$ International Symposium on UHPC and Nanotechnology for High Performance Construction Materials, 7-9 March 2012, Kassel, Germany, 889-896.
Htut, T. N. S.; Foster, S. J. 2010. Unified model for mixed mode fracture of steel fiber reinforced concrete, in Proc. of Fracture Mechanics of Concrete and Concrete Structures - High Performance, Fiber Reinforced Concrete, Special Loadings and Structural Applications, 23-28 May 2010, Korea Concrete Institute, Korea, 1469-1477.

Justs, J.; Wyrzykowski, M.; Winnefeld, F.; Bajare, D.; Lura, P. 2014. Influence of superabsorbent polymers on hydration of cement pastes with low water-to-binder ratio: a calorimetry study, Journal of Thermal Analysis and Calorimetry 115(1): 425-432. http://dx.doi.org/10.1007/s10973-013-3359-x

Kononova, O.; Lusis, V.; Galushchak, A.; Krasnikovs, A.; Machanovsky, A. 2012. Numerical modelling of fiber pull-out micromechanics in concrete matrix composites, Journal of Vibroengineering 14(4): 1852-1861.

Krasnikovs, A.; Khabaz, A.; Kononova, O. 2009. Numerical 2D Investigation of Non-metallic (glass and carbon) fiber micro-mechanical behavior in concrete matrix, Construction Science 10: 67-78.

http://dx.doi.org/10.2478/v10137-009-0007-z

Krasnikovs, A.; Khabaz, A.; Telnova, I.; Machanovsky, A.; Klavinsh, I. 2010. Numerical 3D investigation of nonmetallic (glass, carbon) fiber pull-out micromechanics (in concrete matrix), Mechanics 33: 103-108.

Li, V. C. 1992. Postcrack scaling relations for fiber reinforced cementitious composites, Journal of Materials in Civil Engineering 4(1): 41-57.

http://dx.doi.org/10.1061/(ASCE)0899-1561(1992)4:1(41)

Li, C.; Mobasher, B. 1998. Finite element simulations of fiber pull-out toughening in fiber reinforced cement based composites, Advanced Cement Based Materials 7(3-4): 123132. http://dx.doi.org/10.1016/S1065-7355(97)00087-4

Li, V. C.; Stang, H. 1997. Interface property characterization and strengthening mechanisms in fiber reinforced cement based composites, Advanced Cement Based Materials 6(1): 1-20. http://dx.doi.org/10.1016/S1065-7355(97)90001-8

Li, V. C.; Stang, H.; Krenchel, H. 1993. Micromechanics of crack bridging in fibre-reinforced concrete, Materials and Structures 26(8): 486-494. http://dx.doi.org/10.1007/BF02472808

LVS EN 12390-3:2002. Testing hardened concrete - part 3: compressive strength of test specimens. LVS/STK/15, The Latvia Road Technical Committee of Standartization, Latvijas Standarts.

Mobasher, B.; Li, C. Y. 1995. Modelling of stiffness degradation of the interfacial zone during fiber debonding, Composites Engineering 5(10-11): 1349-1365. http://dx.doi.org/10.1016/0961-9526(95)00056-S

Naaman, A. E.; Wille, K. 2012. The path to ultra-high performance fiber reinforced concrete (UHP-FRC): five decades of progress, in Ultra-High Performance Concrete and $\mathrm{Na}$ notechnology in Construction, Proceedings of Hipermat 2012, $3^{\text {rd }}$ International Symposium on UHPC and Nanotechnology for High Performance Construction Materials Symopsium, 7-9 March 2012, Kassel, Germany, 3-15.

Pupurs, A. 2012. Micro-crack initiation and propagation in fiber reinforced composites: Doctoral thesis. Luleå Tekniska Universitet, Luleå. 174 p.

Pupurs, A.; Varna, J.; Krasnikovs, A. 2013. Energy release rate based fiber/matrix debond growth in fatigue. Part II: debond growth analysis using Paris law, Mechanics of Advanced Materials and Structures 20(4): 288-296. http://dx.doi.org/10.1080/15376494.2011.627628

Sanchez, F.; Sobolev, K. 2010. Nanotechnology in concrete a review, Construction and Building Materials 24(11): 2060-2071. http://dx.doi.org/10.1016/j.conbuildmat.2010.03.014 
Sasmal, S.; Bhuvaneshwari, B.; Iyer, N. R. 2013. Can carbon nanotubes make wonders in civil/structural engineering, Progress in Nanotechnology and Nanomaterials 2: 117129. http://dx.doi.org/10.5963/PNN0204003

Schmidt, M.; Fehling, E. 2005. Ultra-high-performance concrete: Research, development and application in Europe, in Seventh International Symposium on the Utilization of High Strength/High-Performance Concrete, 20-24 June 2005, Washington D.C., USA, 51-78.

Stang, H.; Li, V. C.; Krenchel, H. 1995. Design and structural applications of stress-crack width relations in fibre reinforced concrete, Materials and Structures 28(4): 210-219. http://dx.doi.org/10.1007/BF02473251
Šahmenko, G.; Pupurs, A.; Kononova, O.; Krasņikovs, A. 2007. Non-linear post-cracking behaviour prediction method for high concentration steel fibre reinforced concrete (HCSFRC) beams, Construction Science 8: 60-70.

Wille, K.; Loh, K. J. 2010. Nanoengineering ultra-high-performance concrete with multiwalled carbon nanotubes, Transportation Research Record: Journal of the Transportation Research Board 2142: 119-126. http://dx.doi.org/10.3141/2142-18

Wille, K.; Naaman, A. E. 2010. Bond-slip behavior of steel fibers embedded in ultra high performance concrete, in Proc. of the $18^{\text {th }}$ European Conference on Fracture and Damage of Advanced Fiber-Reinforced Cement-Based Materials, Contribution to ECF 18, September 2010, Dresden, Germany. Freiburg: Aedificatio Publishers, 99-111.

Olga KONONOVA. Dr Sc. Ing. (PhD) in Mechanics received in 2005, professor since 2012. Fields of interest; material mechanics, composite materials, concretes, experimental investigations and numerical modelling. Author of more than 100 scientific publications and 7 invention patents. Participant of four EU research projects and leader of seven domestic research projects. Author and co-author of more than 20 Scopus referenced papers.

Andrejs KRASNIKOVS. Professor, Corresponding Member of the Latvian Academy of Sciences. Dr Sc. Ing. (PhD) in Mathematics and Physics received in 1986. Head of Concrete Mechanics Laboratory since 2000, professor since 2006. Visiting professor of Virginia Tech (US) (2000); visiting researcher of Lulea Tech (Sweden) (2002). Academic fields of interest: materials mechanics, composite materials, nano-materials, concretes, asphalts, experimental mechanics and numerical investigations. Author of more than 180 scientific publications and 25 invention patents. During the last five years, RTU contractor and tasks leader in three large international and more than ten regional scientific research projects.

Rimvydas STONYS. Dr, Senior Researcher, Laboratory of Building Products Technology, Scientific Institute of Thermal Insulation of Vilnius Gediminas Technical University, Lithuania. Research interests: materials science, application of nanotechnologies in cementitious materials, refractory concretes and their application.

Genadijs SAHMENKO. In 1991, he graduated the Faculty of Civil Engineering of Riga Technical University. In 1995, he received the Master's Degree in Engineering Sciences. In 2005, he was awarded the Doctor's Degree in Engineering Sciences in the field of the Construction Science. Currently, he is a leading researcher of the Department of Building Materials and Products. Fields or research: high performance concrete, self-compacting concrete, eco-insulating materials based on natural fibres. He is a member of the Latvian Concrete Society and the Editor-in-Chief of the RTU Scientific Journal "Construction science".

Renars VITOLS. He graduated from the mechanical engineering of Riga Technical University (RTU) in 2012. He is a PhD student in applied mechanics at RTU. His research goal is to develop a new type of continuous contractile dielectric elastomer actuator. Main fields of interest: mechanics of materials, calculation of stress and strain by FEM, morphing structures and smart materials based on electroactive polymers. 